\section{A simple microscope attachment for making multiple width measurements of long fibres}

\section{E. A. WRIGHT From the Department of Radio- logy, Stanford University School of Medicine, Stanford, California, U.S.A. ${ }^{1}$}

A single measurement of the width of a fibre $(5-100 \mu)$ mounted on a microscope slide can be readily made by using a microscope and an eyepiece micrometer scale. Multiple readings at small intervals $(0.1 \mathrm{~mm}$.) along the fibre using a moving stage fitted with a vernier scale can

'Present address: Department of Pathology, St. Mary's Hospital, London, W.2.

Received for publication 16 March 1965.

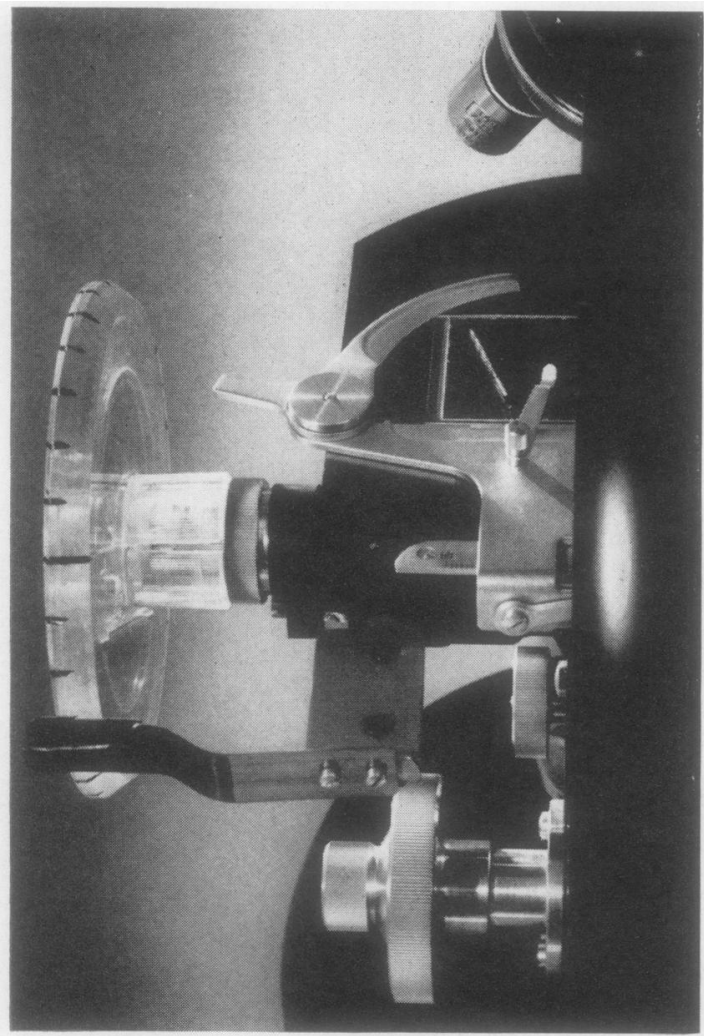

FIG 1. The device fitted to a Zeiss microscope. The plastic protractor is fixed to the knurled knob of the stage controlling lateral movements. Backwards and forwards movements were made by a knob on the other side. The steel spring is lodged in a notch $36^{\circ}$ ' $0.3 \mathrm{~mm}$.' away from the nearest ' $1.0 \mathrm{~mm}$.' notch. The notches have bren enlarged and blackened for purposes of illustration.

\section{Book reviews}

TEXTBOOK OF SURGERY Edited by David A. Macfarlane and Lewis $\mathbf{P}$. Thomas with a Foreword by Norman $\mathbf{C}$. Tanner. (Pp. 772; 395 illustrations. 60s.) Edinburgh and London. E. \& S. Livingstone Ltd. 1964.

This is a book which the authors have directed toward the final year student, with the hope that it will also attract qualified practitioners who may use it as a guide to further study.

Under the general title of 'Surgical aspects of infection and inflammation', there is an all too brief introduction to bacteriology and infections and inflammation. It would be better to omit such basic descriptions altogether than use this potted version. As a pathologist, one would naturally feel that inflammation, which usually needs a whole chapter, bacteriological aspects of acute and chronic infections, and ward, theatre, and hospital cross infection, all deserve more attention than is given.

The chapter on trauma includes an excellent if short description of simple blood grouping and the technique and dangers of transfusion, including the advice to use blood substitutes where possible. The contributors have also provided a masterly introduction to the subject of fluid balance; this is presented in a much more authoritative style, and will certainly be of great value to the young house surgeon.

The greater part of the book takes the surgical condition

A simple microscope attachment for making multiple width measurements of long fibres-concluded

also be made but are very tedious and necessitate frequent reaccommodations of the eye. To overcome this difficulty the horizontal knurled knob operating the transverse movement of the stage of certain Zeiss microscopes can be fitted with a device which allows the amount of transverse movement to be appreciated by ear and sense of touch (Fig.). It consists of a circular plastic protractor $(10 \mathrm{~cm}$. diameter) attached to a perspex sleeve that fits tightly over the knurling of the knob. (One revolution of this disc caused $3 \mathrm{~mm}$. of lateral movement so that 12 degrees equalled $0.1 \mathrm{~mm}$.). The disc was notched lightly every 12 degrees $(0.1 \mathrm{~mm}$.) and more heavily each 120 degrees $(1.0 \mathrm{~mm}$.) so that a spring steel arm clicked into the notches. Thus, without taking one's eyes from the microscope image many measurements at $0.1 \mathrm{~mm}$. intervals could be made. The overall lateral movement was checked occasionally with the stage vernier to guard against mistakes. Another convenience of this method was that the readings could be started from a $1.0 \mathrm{~mm}$. notch by appropriately fitting the sleeve, thus avoiding much subsequent subtraction if the results were to be plotted from one end of the fibre.

The cost of the plastic protractor and spring were negligible. 